CLINICAL STUDY

\title{
Craniofacial and brain abnormalities in Laron syndrome (primary growth hormone insensitivity)
}

\author{
L Kornreich, G Horev, M Schwarz, B Karmazyn and Z Laron ${ }^{1}$ \\ Imaging Department and ${ }^{1}$ Endocrinology and Diabetes Research Unit, Schneider Children's Medical Center of Israel, Petah Tiqva, Sackler Faculty of \\ Medicine, Tel Aviv University, Tel Aviv, Israel
}

(Correspondence should be addressed to L Kornreich, Imaging Department, Schneider Children's Medical Center of Israel, Petah Tiqva 49202, Israel)

\begin{abstract}
Objective: To investigate abnormalities in the craniofacial structures and in the brain in patients with Laron syndrome.

Design: Eleven patients with classical Laron syndrome, nine untreated adults aged 36-68 years and two children aged 4 and 9 years (the latter treated by IGF-I), were studied.

Methods: Magnetic resonance images of the brain were obtained in all the patients. One patient also underwent computed tomography. The maximal diameter of the maxillary and frontal sinuses was measured and compared with reference values, the size of the sphenoid sinus was evaluated in relation to the sella, and the mastoids were evaluated qualitatively (small or normal). The brain was evaluated for congenital anomalies and parenchymal lesions.

Results: In the adult untreated patients, the paranasal sinuses and mastoids were small; in six patients, the bone marrow in the base of the skull was not mature. The diploe of the calvaria was thin. On computed tomography in one adult patient, the sutures were still open. A minimal or mild degree of diffuse brain parenchymal loss was seen in ten patients. One patient demonstrated a lacunar infarct and another periventricular high signals on T2-weighted images. Two patients had cerebellar atrophy.

Conclusions: The present study has demonstrated the important role IGF-I plays in the development of the brain and bony structures of the cranium.
\end{abstract}

European Journal of Endocrinology 146 499-503

\section{Introduction}

Laron syndrome (LS), also known as primary growth hormone $(\mathrm{GH})$ resistance or insensitivity syndrome (1, 2 ), is an autosomal recessive disease caused by deletions (3) or mutations in the $\mathrm{GH}$ receptor gene $(4,5)$ or the post-receptor pathways (6). The defects in GH signal transmission lead to an inability to generate insulin-like growth factor-I (IGF-I) (7). Therefore, affected patients fail to respond to $\mathrm{GH}$ of either endogenous or exogenous origin. The clinical features of LS are indistinguishable from those of untreated isolated GH deficiency; however, patients with LS have high serum levels of GH and undetectable serum IGF-I $(8,9)$.

Clinically, LS is manifested by dwarfism, acromicria and organomicria $(8-11)$. Craniofacial abnormalities include subnormal head circumference $(10,11)$ and underdevelopment of the facial bones $(12,13)$. The physiognomy is characteristic: prominent forehead, decreased vertical dimension of face, hypoplastic nasal bridge, shallow orbits and small maxilla and mandible (1, 9-11). Motor and psychological development are slow, intelligence studies in large group of patients have revealed a great variability, with a lower than normal distribution (14).

Two of the LS patients in our center who are mentally retarded and others who suffer from recurrent headaches were referred for imaging of the brain. The aim of the present study was to report for the first time the abnormal findings on magnetic resonance (MR) of the head in patients with LS.

\section{Materials and methods}

\section{Subjects}

The study included 11 patients with LS. Diagnosis was based on the presence of severe short stature with a high basal level of $\mathrm{GH}$ and low serum level of IGF-I. There were six females and five males, including nine adults aged 36-68 years and two children, a boy aged 4 years and a girl 9 years. The latter patient had been treated with IGF-I (150-180 mg/kg per day) since 3 years of age, all other patients were 
Table 1 Pertinent clinical data of patients with LS.

\begin{tabular}{ccll}
\hline Patient no. & $\begin{array}{c}\text { Sex/age } \\
\text { (years) }\end{array}$ & Clinical complaints & Comments \\
\hline Untreated & & & \\
1 & $\mathrm{M} / 4$ & & \\
2 & $\mathrm{M} / 36$ & & Sibling of no. 6 \\
3 & $\mathrm{M} / 41$ & Headache & Sibling of no. 7 \\
4 & $\mathrm{M} / 46$ & Ataxia, mental retardation & Sibling of no. 8 \\
5 & $\mathrm{M} / 68$ & & \\
6 & $\mathrm{~F} / 39$ & Headache & Sibling of no. 2 \\
7 & $\mathrm{~F} / 42$ & Headache & Sibling of no. 3 \\
8 & $\mathrm{~F} / 43$ & Mental retardation & Sibling of no. 4 \\
9 & $\mathrm{~F} / 44$ & Headache & \\
10 & $\mathrm{~F} / 48$ & & \\
IGF-I treated & & & \\
11 & $\mathrm{~F} / 9$ & Seizures & \\
\hline
\end{tabular}

$\mathrm{M}=$ male; $\mathrm{F}=$ female

untreated. Table 1 shows the pertinent clincial data of the patients.

\section{Methods}

All patients underwent MR imaging of the brain, and one (patient no. 7) also had computed tomography (CT). We used an MR system operating at $0.5 \mathrm{~T}$. The imaging protocol included axial T2-weighted FSE images (repetition time (TR) $4000 \mathrm{~ms}$, echo time (TE) $100 \mathrm{~ms}$, echo train 8) and T1-weighted axial, coronal and sagittal images (TR $450 \mathrm{~ms}$, TE $25 \mathrm{~ms}$ ) of the brain. Contrast agent was not injected. The scans were initially read independently by two radiologists, and then reviewed together until a consensus was reached. The size of the frontal, maxillary and sphenoid sinuses and also of the mastoids was evaluated. The frontal and maxillary sinuses were graded as undeveloped or aerated but smaller than $1 \mathrm{~cm}$ in diameter; if larger than $1 \mathrm{~cm}$, the diameter was measured and compared with reference values (15). The sphenoid sinus was considered small when the aeration did not include the infrasellar region, which should be aerated by 10 years of age (16). The mastoids were evaluated qualitatively as small or normal. Abnormalities of the skull were also noted. The brain was examined for congenital anomalies or parenchymal lesions. Parenchymal loss was graded visually as minimal, slight, moderate or severe.

\section{Results}

\section{Craniofacial structures}

The diploe of the calvarial bones was thin in all the patients (Fig. 1). Evaluation of the size of the sinuses and mastoids is given in Table 2 (see also Fig. 2). No reference values for the size of the sinuses were available for the children; however, it is noteworthy that in the treated girl the size of the maxillary sinus was already very close to that of the adult females with LS. In the adult patients, there were signs of retarded maturation of the skull: in six patients the clivus and the basisphenoid did not show a fatty bone marrow, as appropriate for age (Table 2). In three patients, there was a faint remnant of the spheno-occipital

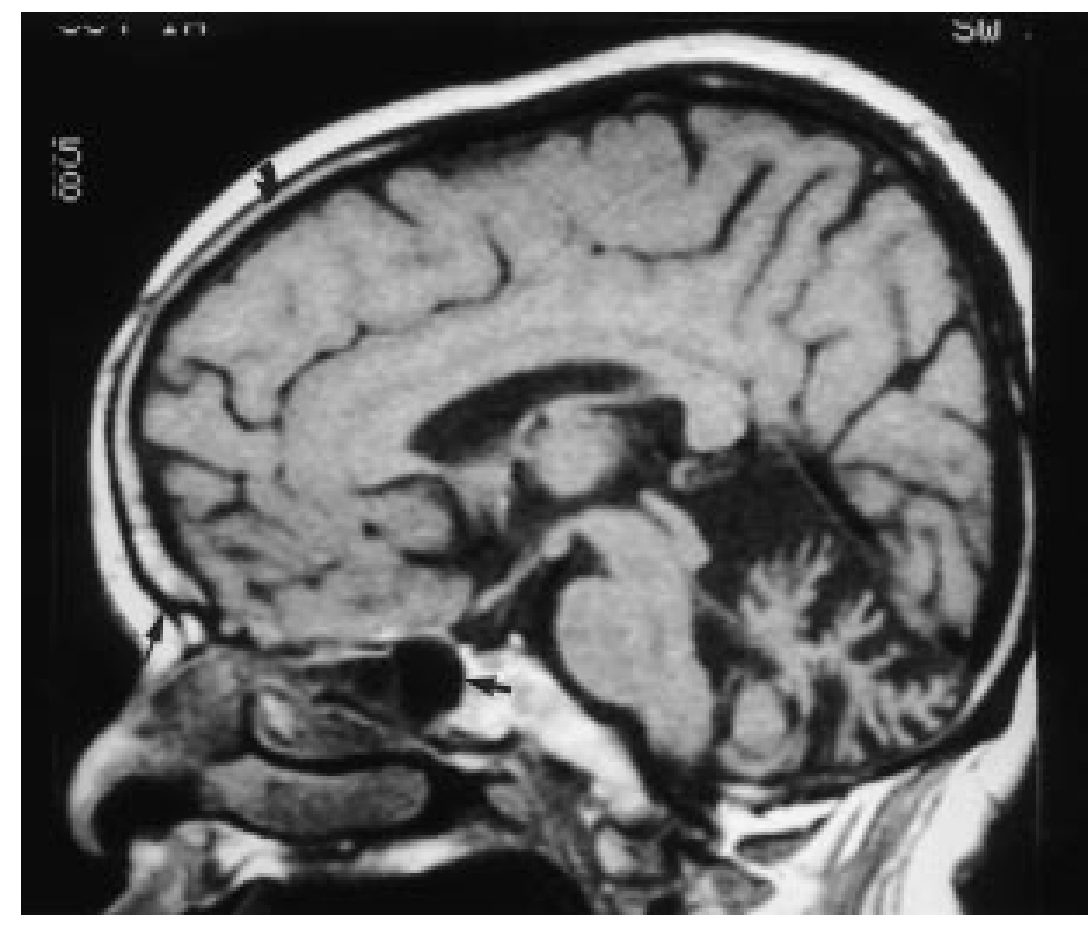

Figure 1 Patient no. 8. Sagittal T1-weighted MR image shows a thin diploe (curved arrow), absent frontal sinuses (thin arrow) and a small spheroid sinus (thicker arrow). Note also the atrophy of the cerebellum. 
Table 2 Craniofacial findings in patients with LS.

\begin{tabular}{|c|c|c|c|c|c|c|}
\hline \multirow[b]{2}{*}{ Patient no. } & \multicolumn{2}{|c|}{ Frontal sinus } & \multicolumn{2}{|c|}{ Maxillary sinus (cm) } & \multirow[b]{2}{*}{ Sphenoid sinus and mastoid } & \multirow[b]{2}{*}{ Bone marrow base of skul } \\
\hline & AP & ML & $\mathrm{AP}$ & ML & & \\
\hline \multicolumn{7}{|c|}{ Adults untreated } \\
\hline 2 & \multicolumn{2}{|c|}{$<1 \mathrm{~cm}$} & 3 & 2 & Small & Not fatty \\
\hline 3 & \multicolumn{2}{|c|}{ None } & 3 & 1.5 & Small & Fatty \\
\hline 4 & \multicolumn{2}{|c|}{ None } & 2.5 & 1.8 & Small & Not fatty \\
\hline 5 & \multicolumn{2}{|c|}{ None } & 2.8 & 1.2 & Small & Fatty \\
\hline 6 & \multicolumn{2}{|c|}{ None } & 2.5 & 1.5 & Small & Not fatty \\
\hline 7 & \multicolumn{2}{|c|}{$<1 \mathrm{~cm}$} & 3 & 1 & Small & Partially fatty \\
\hline 8 & \multicolumn{2}{|c|}{ None } & 2.8 & 1.8 & Small & Fatty \\
\hline 9 & \multicolumn{2}{|c|}{ None } & 2.4 & 1.8 & Small & Not fatty \\
\hline 10 & \multicolumn{2}{|c|}{$<1 \mathrm{~cm}$} & 2 & 1.5 & Small & Not fatty \\
\hline \multicolumn{7}{|c|}{ Normal values } \\
\hline $\mathrm{M}$ & $1.55-1.81$ & $2.54-3.05$ & $3.33-4.37$ & $2.66-3.81$ & & \\
\hline $\mathrm{F}$ & $1.3-1.76$ & $2.08-3.04$ & $3.30-4.40$ & $2.40-3.64$ & & \\
\hline \multicolumn{7}{|c|}{ Children untreated } \\
\hline 1 & \multirow{2}{*}{\multicolumn{2}{|c|}{ None }} & 1.5 & 0.6 & None & \\
\hline IGF-1-treatec & & & & & & \\
\hline 11 & \multicolumn{2}{|c|}{$<1 \mathrm{~cm}$} & 2.4 & 1.5 & & \\
\hline
\end{tabular}

$\mathrm{AP}=$ anterior posterior $\mathrm{ML}=$ mediolateral $\mathrm{M}=$ male; $\mathrm{F}=$ female.

synchondrosis (Table 2). On the single available CT scan (patient no. 7), the sutures of the calvaria were not completely closed, despite the advanced age of the patient (Fig. 3).

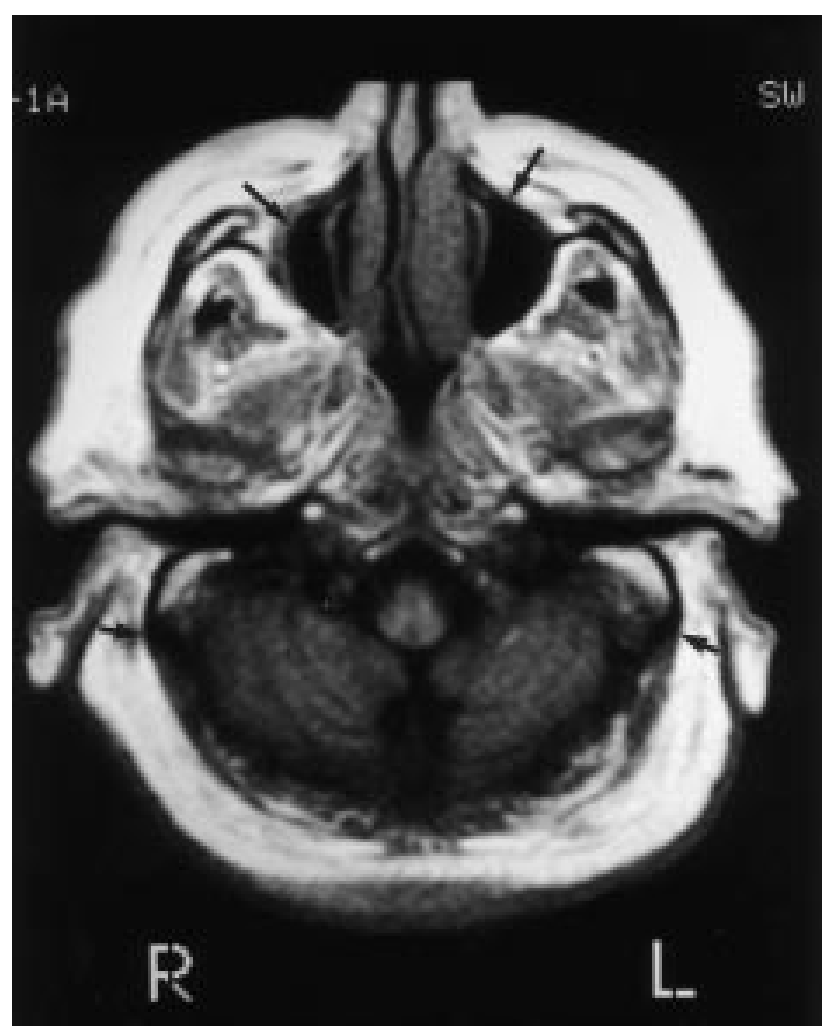

Figure 2 Patient no. 5. Axial T2-weighted MR image shows small maxillary sinuses (arrows) and mastoids (shorter arrows).

\section{Brain}

The intracranial findings are summarized in Table 3. In two sibling patients, the cerebellum was symmetrically small with enlarged foliae and fissures, compatible with cerebellar atrophy. A minimal to slight degree of diffuse parenchymal loss was seen in ten patients (Fig. 4). One patient demonstrated a lacunar infarct in the right caudate nucleus. Patient no. 8, who suffered from mental retardation, had regions of posterior periventricular high signal on T2-weighted images. No midline anomalies were detected.

\section{Discussion}

LS is a unique model for the study of congenital IGF-I deficiency. Our study presents several new findings in this syndrome. In addition to the known small head circumference $(1,11)$ and underdevelopment of the facial structures $(12,13)$, we document for the first time the marked retardation of skeletal maturation, manifesting as delayed closure of sutures and synchondroses, which normally close by the third decade (16). The sagittal suture was still visible in a 42 -year-old patient (in the only CT available), and the spheno-occipital synchrondrosis was faintly discernible in three patients aged 36, 42 and 46 years. An additional sign of delayed maturation was a thin cranial vault, with a relatively under-developed diploe for this age group. In five patients, the bone marrow of the base of the skull was not fatty, as expected, but showed an intensity compatible with active hematopoietic marrow. In all our patients, the sphenoid sinus was also underdeveloped. 


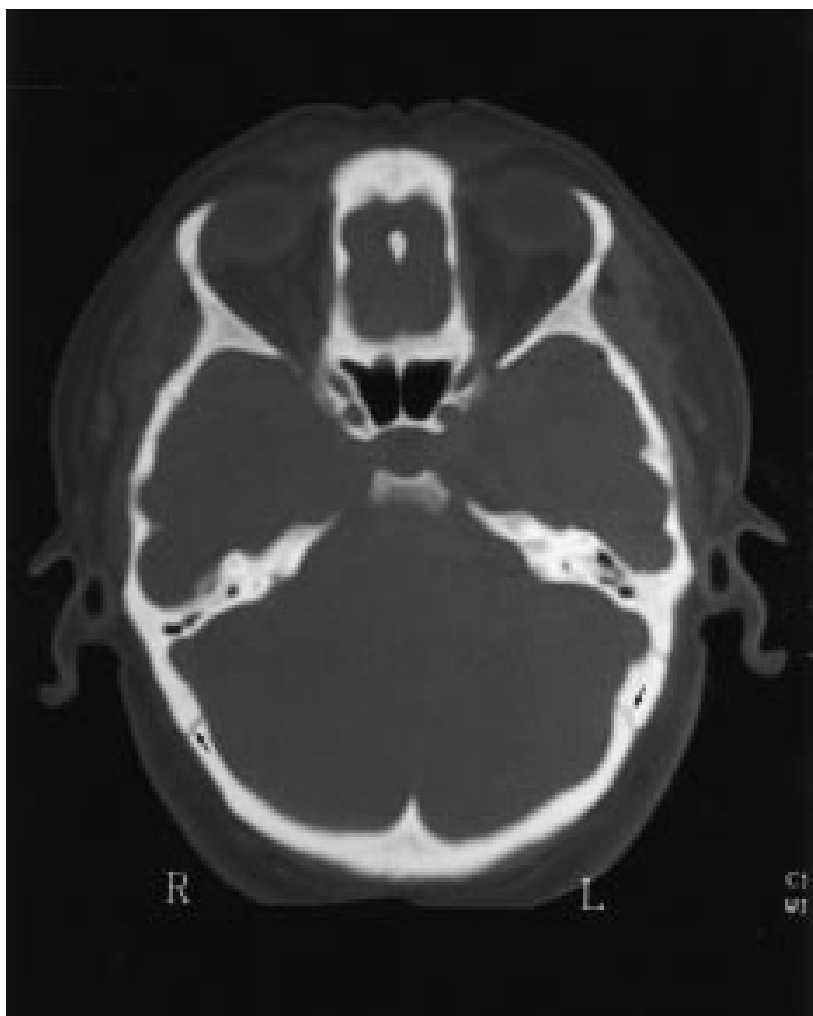

Figure 3 Patient no. 7. Axial CT image shows open sutures (arrows).

Overall, these findings point to a disturbance in the process of growth and maturation of the bone marrow in the skull in LS patients. Other regions of axial as well as peripheral bone marrow should also be examined by MR studies to further assess the influence of IGF-I deficiency on the extent and maturation of the hematopoietic bone marrow.

Other skeletal abnormalities found were the absence or under-development of the maxillary and frontal sinuses. All these findings must be attributable to the IGF-I deficiency starting in utero.

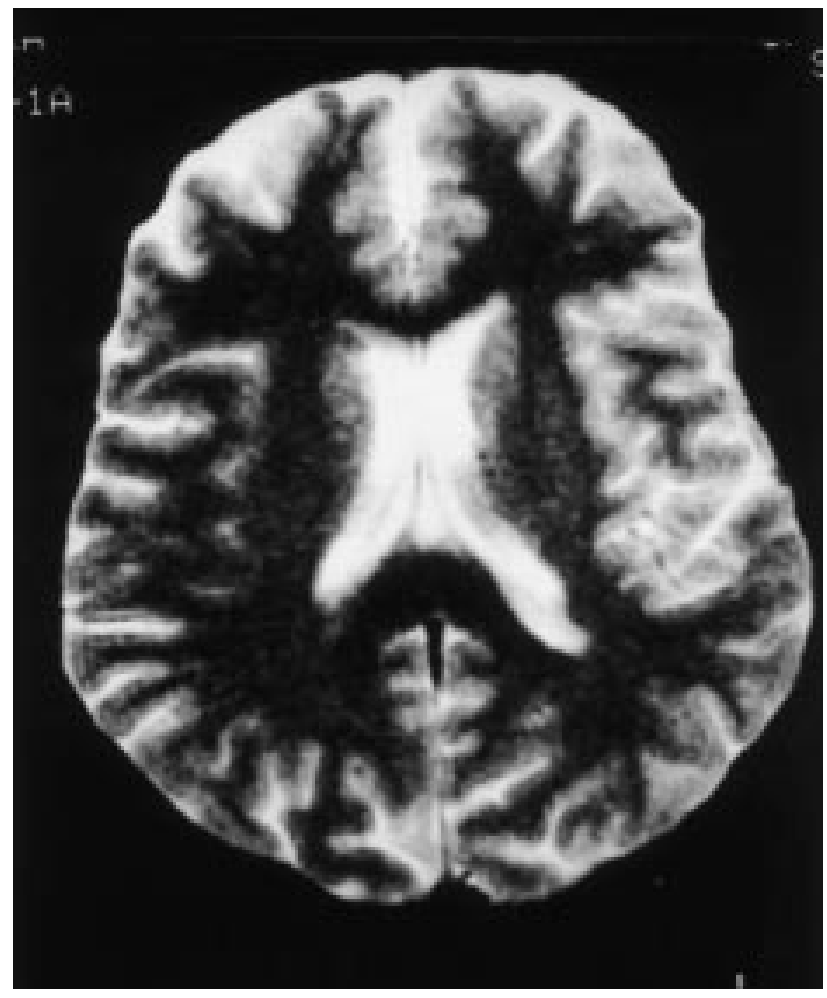

Figure 4 Patient no. 9. Axial T2-weighted MR image shows minimal diffuse parenchymal loss.

In the nervous tissue of the brain, we found changes of diffuse parenchymal loss of various degrees, mostly minimal or slight, although, in one patient, periventricular leukomalacia was present. These findings seem to parallel the wide spectrum of intellectual abilities of patients with long-term IGF-I deficiency (14); however, whether they are directly related is not known at present. It is of interest that the patient with the most severe damage (patient no. 8) resides in an institution for the mentally retarded. Also interestingly is that the two siblings with mental retardation showed

Table 3 Brain abnormalities in patients with LS.

\begin{tabular}{ccl}
\hline Patient no. & Diffuse parenchymal loss & \multicolumn{1}{c}{ Additional findings } \\
\hline Untreated & Minimal & \\
1 & Minimal & \\
2 & Minimal & Atrophy of cerebellum \\
3 & No & Ubos, compatible with age \\
4 & Slight & \\
5 & Slight & Lacunar infarct in right caudate \\
6 & Minimal & Atrophy of cerebellum, T2 posterior periventricular hyperintensity \\
7 & Slight & \\
8 & Minimal & \\
9 & Minimal & \\
10 & & \\
IGF-1 treated & Minimal & \\
11 &
\end{tabular}

Ubo $=$ undefined bright object 
cerebellar atrophy. These pathologies do not seem specific as similar findings are found in numerous metabolic disorders which affect the cerebellum and cause cerebellar atrophy (16). It should be stressed that the abnormal findings in the brain are not similar to damage secondary to neonatal hypoglycemia which is characteristic for young LS patients $(9,11,17)$.

Despite the small head circumference, characteristic of patients with LS, no significant brain atrophy was demonstrated. The vault of the skull normally develops by membranous ossification, and its growth is triggered by the development of the brain (18); as the child's brain grows, the calvarial bones are displaced and new bone is deposited in the sutural edges. If there is arrest of brain growth, the sutures close (18). However, in LS, microcephaly accompanies delayed closure of the sutures. Earlier researchers assumed that the microcrania in LS was secondary to under-development of the brain tissue due to the early onset and continuous IGF-I deficiency (19), an assumption proven by the rapid increase in head circumference in response to IGF-I treatment in children (20). Our findings further support the important role of IGF-I in the development of the central nervous tissue.

In conclusion, the present report, using MR imaging of the skull and brain of patients with LS (primary IGF-I deficiency) demonstrated the developmental pathology induced by congenital and continuing IGF-I deficiency to the development of the central nervous system and cranial structures.

\section{References}

1 Laron Z. Laron syndrome - primary growth hormone resistance. In Contemporary Endocrinology pp 17-37. Ed. JL Jameson. Totowa: Humana Press, 1999.

2 Laron Z, Blum W, Chatelain P, Ranke M, Rosenfeld R, Savage M et al. Classification of growth hormone insensitivity syndrome. Journal of Pediatrics 1993122241.

3 Godowski PJ, Leung DW, Meacham LR, Galgani JP, Hellmiss R, Keret $\mathrm{R}$ et al. Characterization of the human growth hormone receptor gene and demonstration of a partial gene deletion in 2 patients with Laron type dwarfism. PNAS 198986 8083-8087.

4 Rosenfeld RG, Rosenbloom AL \& Guevara-Aguirre J. Growth hormone $(\mathrm{GH})$ insensitivity due to primary $\mathrm{GH}$ receptor deficiency. Endocrine Reviews 199415 369-390.

5 Amselem S, Sobrier ML, Dastot F, Duquesnoy O, Duriez B \& Goossens M. Molecular basis of inherent growth hormone resistance in childhood. Baillière's Clinical Endocrinology and Metabolism $199610353-369$.

6 Laron Z, Klinger B, Eshet R, Kanety H, Karasik A \& Silbergeld A. Laron syndrome due to a post-receptor defect: response to IGF-1 treatment. Israel Journal of Medical Sciences 199329 757-763.
7 Laron Z, Pertzelan A, Karp M, Kowadlo-Silbergeld A \& Daughaday WH. Administration of growth hormone to patients with familial dwarfism with high plasma immunoreactive growth hormone. Measurement of sulfation factor, metabolic, and linear growth responses. Journal of Clinical Endocrinology and Metabolism $197133332-342$.

8 Laron Z, Pertzelan A \& Mannheimer S. Genetic pituitary dwarfism with high serum concentration of growth hormone. A new inborn error of metabolism? Israel Journal of Medical Sciences $19662152-155$.

9 Laron Z, Pertzelan A \& Karp M. Pituitary dwarfism with high serum levels of growth hormone. Israel Journal of Medical Sciences $19684883-894$.

10 Laron Z. Laron type dwarfism (hereditary somatomedin deficiency): a review. In Advances in Internal Medicine and Pediatrics, vol 51, pp 117-150. Eds P Frick, G-A Von Harnack, G-A Kochsiek \& A Prader. Berlin, Heidelberg: Springer Verlag, 1984.

11 Laron Z. Natural history of the classical form of primary growth hormone (GH) resistance (Laron syndrome). Journal of Pediatric Endocrinology and Metabolism 199912 231-249.

12 Scharf A \& Laron Z. Skull changes in pituitary dwarfism and the syndrome of familial dwarfism with high plasma immunoreactive growth hormone. A roentgenologic study. Hormone and Metabolic Research $1972493-97$.

13 Konfino R, Pertzelan A \& Laron Z. Cephalometric measurements of familial dwarfism and high plasma immunoreactive growth hormone. American Journal of Orthodontics 197568 196-201.

14 Galatzer A, Aran O, Nagelberg N, Rubitzek \& Laron Z. Cognitive and psychosocial functioning of young adults with Laron Syndrome. In Lessons from Laron Syndrome, edn 1, ch 24, pp 53-60. Eds Z Laron \& JS Parks. Basel: Karger, 1993.

15 Spaeth J, Krugelstein U \& Schlondorff G. The paranasal sinuses in CT-imaging: development from birth to age 25. International Journal of Pediatric Otorhinolaryngology 199739 25-40.

16 Barkovich AJ. Normal development of the neonatal and infant brain, skull and spine. In Pediatric Neuroimaging, edn 3, ch. 2, pp 45-49. Philadelphia: Lippincott Williams \& Wilkins, 2000.

17 Murakami Y, Yamashita Y, Matsuishi T, Utsunomiya H, Okudera T \& Hashimoto T. Cranial MRI of neurologically impaired children suffering from neonatal hypoglycaemia. Pediatric Radiology 1999 $2923-27$.

18 Silverman FN, Byrd SE \& Fitz CR. The skull spine and central nervous system. In Caffey's Pediatric X-ray Diagnosis: An Integrated Imaging Approach, edn 9, ch 1, pp 4-9 and 82-86. Eds FN Silverman \& JP Kahn. St Louis: Mosby, 1992.

19 Laron Z, Lazar L \& Klinger B. Growth hormone, insulin-like growth factor 1 and brain growth and function. In Growth Hormone Treatment in Down's Syndrome, edn 1, ch 12, pp 151-161. Eds S Castells \& KE Wisnewski. New York: John Wiley \& Sons 1993.

20 Laron Z, Anin S, Klipper-Aubach Y \& Klinger B. Effects of insulinlike growth factor on linear growth, head circumference and body fat in patients with Laron-type dwarfism. Lancet 1992339 $1258-1261$.

Received 18 October 2001

Accepted 14 January 2002 